\title{
Nutritional anaemia in pregnant Beninese women: consequences on the haematological profile of the newborn
}

\author{
By SERGE HERCBERG AND PILAR GALÁN \\ Centre de Recherche sur les Anémies Nutritionnelles, ISTA, CNAM, 292 rue St Martin, \\ Paris F-75003, France \\ AND MICHEL CHAULIAC AND ANNE-MARIE MASSE-RAIMBAULT \\ Centre International de l'Enfance, Paris, France \\ AND MICHEL DEVANLAY \\ Hopital Albert Chenevier, Créteil, France \\ AND SEMIOU BILEOMA, EUSEBE ALIHONOU \\ AND ISIDORE ZOHOUN \\ CNHU et Maternité de la Lagune, Cotonou, Benin \\ AND JEAN-PHILIPPE CHRISTIDES \\ AND GENEVIEVE POTIER DE COURCY \\ CNRS, Meudon-Bellevue, France
}

(Received 13 May 1986 - Accepted 2 September 1986)

1. An assessment of iron and folic acid status, blood thick film and haemoglobin (Hb) electrophoresis was performed on 126 pregnant women (and their newborn infants) and in ninety-five menstruating women in Cotonou (Benin).

2. Anaemia (according to the World Health Organization (1972)) was observed in $55 \%$ of pregnant women and in $39 \%$ of menstruating women.

3. Fe-deficiency was defined as a low serum ferritin concentration $(12 \mu \mathrm{g} / 1$ or less), combined with a low transferrin saturation (less than $16 \%$ ) or a high erythrocyte protoporphyrin level (more than $3 \mu \mathrm{g} / \mathrm{g} \mathrm{Hb}$ ), or both. A moderate elevation in the serum ferritin concentration (between 13 and $50 \mu \mathrm{g} / \mathrm{l}$ ), associated with a low transferrin saturation or a high erythrocyte protoporphyrin level, or both, indicated Fe-deficiency in an inflammatory context. Fe-deficiency was present in $73 \%$ of pregnant women and in $41 \%$ of menstruating women.

4. Folate deficiency (defined as erythrocyte folate below $160 \mu \mathrm{g} / 1$ ) was observed in $45 \%$ of pregnant women.

5. In pregnant women, anaemia was associated with Fe-deficiency in $83 \%$ of cases and with folate deficiency in $48 \%$ of cases.

6. Haemoglobinopathies were mainly heterozygous and did not seem to contribute significantly to anaemia. Intensity of malaria was not related to $\mathrm{Hb}$ level, but Plasmodium falciparum was found in $99 \%$ of subjects.

7. $\mathrm{Hb}$ concentration and mean corpuscular volume were significantly lower in babies born of Fe-deficient mothers than in babies born of Fe-sufficient mothers. $\mathrm{Hb}$ concentration in newborn infants was positively correlated with maternal serum ferritin.

Although nutritional anaemia is prevalent worldwide, it is particularly common in developing countries (DeMaeyer \& Adiels-Tegman, 1985). Pregnant women are among the groups most at risk of developing nutritional anaemia (World Health Organization, 1972). Pregnancy imposes a substantial burden on the maternal haematopoietic system because of the need for augmented erythropoiesis in the face of an expanding plasma volume and obligatory placental transfer of the two most important micronutrients involved, iron and folic acid. Fe-deficiency is classically described as by far the most important aetiological factor of anaemia in pregnancy (Baker \& DeMaeyer, 1979). However, and particularly in 
Table 1. Demographic and anthropometric data of Beninese mothers and newborn infants (n 126)

\begin{tabular}{|c|c|c|c|}
\hline & Mean & SD & Range \\
\hline \multicolumn{4}{|l|}{ Mothers } \\
\hline Age (years) & $25 \cdot 0$ & $5 \cdot 6$ & $16-38$ \\
\hline Weight $(\mathrm{kg})$ & $58 \cdot 8$ & $10 \cdot 1$ & $38-88$ \\
\hline Height $(\mathrm{m})$ & 1.585 & 0.067 & $1 \cdot 38-1 \cdot 74$ \\
\hline Parity (births) & $1 \cdot 6\left(1 \cdot 0^{*}\right)$ & 1.9 & $0-9$ \\
\hline \multicolumn{4}{|l|}{ Newborn infants } \\
\hline Birth weight (g) & 3067 & 403 & $1700-4220$ \\
\hline Length $(\mathrm{m})$ & 0.492 & 0.022 & $0.41-0.54$ \\
\hline Head circumference $(\mathrm{mm})$ & 341 & 22 & $280-580$ \\
\hline Gestational age (weeks) & $39 \cdot 0$ & $1 \cdot 3$ & $32-43$ \\
\hline
\end{tabular}

* Median.

a tropical context, other causes of anaemia are possible: other types of nutritional deficiency (mainly folic acid deficiency); inflammatory syndromes and infections (including malaria, bacterial and viral infections); and sickle cell diseases. Moreover, most of these can also affect the significance of the different biochemical indicators of $\mathrm{Fe}$ status (Hercberg \& Galán, 1985). These interfering factors, very common in Africa, might be responsible for false-positive or false-negative results in the diagnosis of Fe-deficiency and Fe-deficiency anaemia. Difficulties in defining the Fe status and in recognizing Fe-deficiency could explain the conflicting results of previous studies concerning the influence of the maternal Fe balance on fetal Fe status. The use of a number of laboratory measurements leads to improved accuracy in $\mathrm{Fe}$ status assessment and allows separation of Fe-deficient from Fe-sufficient subjects.

The purpose of the present investigation was (1) to specify the relative contribution of the aetiological factors to anaemia in a group of pregnant women in Benin, and (2) to determine the consequences of Fe-deficiency in terms of the haematological profile of newborn infants.

\section{MATERIALS AND METHODS}

\section{Subjects}

The sample was composed of 126 pregnant women (and later their newborn infants) from the two public maternity wards in Cotonou (Benin). Maternal age, weight, height and parity, and birth weight, length and gestational age of the newborn infants are listed in Table 1 . Of the women, $42 \%$ were nulliparous and $20 \%$ had three children or more. All women had normal pregnancies and deliveries. None received $\mathrm{Fe}$ or folic acid supplementation, nor drugs likely to modify their $\mathrm{Fe}$ or folic acid status during the pregnancy in question. Ninety-five menstruating women, mean age 27.3 (SD 5.8) years, chosen randomly from a district of Cotonou were studied as a control group for biological values. Informed consent was obtained from each subject. The survey was performed at the end of the dry season.

\section{Biochemical methods}

Maternal venous blood sampling $(10 \mathrm{ml})$ was carried out on each mother during the first stage of labour. In newborn infants, blood $(450 \mu \mathrm{l})$ was collected by heel prick within the first day of life. Blood samples were collected by venipuncture in the control group. 
Several assays were performed within the $12 \mathrm{~h}$ following blood collection: haemoglobin $(\mathrm{Hb})$ concentration, erythrocyte indices and leucocyte counts using a Coulter Counter (Coultronic, Margency, France) model S; packed cell volume using microcentrifugation; erythrocyte protoporphyrin using an automatic model 5 haematofluorometer (Aviv Biomedical; Analys, Namur, Belgium), and $\mathrm{Hb}$ electrophoresis using cellulose acetate (Helena Corp.; Helena France, St Leu-La-Forêt). Blood thick films were read after coloration by the May-Grünwald Giemsa technique.

Serum fractions were collected by centrifugation, frozen at $-20^{\circ}$ and sent to France in dry ice for different assays: serum Fe concentration was measured by a colorimetric method using ferrozine (Giovanello et al. 1968); transferrin by an automated immunoturbidimetric technique; and total Fe-binding capacity was calculated (Vernet-Nyssen et al. 1983). The serum ferritin level was determined in duplicate using an enzyme-linked immunosorbent assay (Voller \& de Savigny, 1981). Whole blood and serum folate concentrations were estimated by microbiological assay using Lactobacillus casei (Hoffbrand et al. 1966). Erythrocyte folate was calculated using packed cell volume. Serum and erythrocyte folate concentrations were not measured in the control group and serum folate concentration was not measured in newborn infants.

The Coulter Counter was calibrated each week by the Coulter $4 \mathrm{C}$ control; the haematofluorometer was calibrated daily with standards supplied by the manufacturer. Serum ferritin was standardized using international references (NIBSC, London).

\section{Statistical methods}

Statistical analysis was carried out using Student's $t$ test, $\chi^{2}$ test and Pearson's correlation coefficient, $r$. Since serum ferritin, and erythrocyte and serum folate concentrations approached a log normal distribution, a log transformation of these variables was used for all calculations. Results are presented in original units.

\section{Definitions}

Fe-deficiency was defined as a low serum ferritin level $(12 \mu \mathrm{g} / 1$ or less), combined with a low transferrin saturation coefficient (less than $16 \%$ ) or a high erythrocyte protoporphyrin level (above $3 \mu \mathrm{g} / \mathrm{g}$ of haemoglobin), or both. Fe depletion was considered when a low serum ferritin level was not associated with abnormalities of other variables of $\mathrm{Fe}$ status. An inflammatory syndrome was suggested by a high serum ferritin level (above $50 \mu \mathrm{g} / \mathrm{l}$ ), associated with a low transferrin saturation coefficient or a high erythrocyte protoporphyrin concentration, or both. The existence of a low transferrin saturation coefficient or a high erythrocyte protoporphyrin concentration, or both, with a moderate serum ferritin level (between 13 and $50 \mu \mathrm{g} / \mathrm{l}$ ) indicated Fe-deficiency associated with inflammation. Subjects which had no abnormal values for the three independent indicators of $\mathrm{Fe}$ status were considered as 'Fe-sufficient'.

\section{RESULTS}

\section{Maternal Fe status}

Means, with their standard deviations (SD), and percentage of abnormal values for the indicators of $\mathrm{Fe}$ status of pregnant women and the control group of non-pregnant women are given in Table 2.

Anaemia, according to the World Health Organization (1972), was observed in sixty-nine $(55 \%)$ pregnant women and in thirty-seven $(39 \%)$ menstruating women. The percentage of Fe-sufficient, Fe-depleted and Fe-deficient (with or without inflammatory syndrome) subjects among pregnant women and the control group are shown in Table 3. Fe-deficiency 
Table 2. Measurements of iron status in pregnant and non-pregnant Beninese women

\begin{tabular}{|c|c|c|c|c|}
\hline & Mean & SD & Range & $\begin{array}{c}\text { Values } \\
\text { below normal* } \\
(\%)\end{array}$ \\
\hline \multicolumn{5}{|c|}{ Pregnant women ( $n$ 126) } \\
\hline Haemoglobin $(\mathrm{Hb} ; \mathrm{g} / \mathrm{l})$ & 105 & 16 & $59-133$ & $55^{*}$ \\
\hline Mean corpuscular volume (f) & $82 \cdot 1$ & $9 \cdot 1$ & $59-114$ & $41+$ \\
\hline Percent saturation of transferrin & $13 \cdot 2$ & $8 \cdot 4$ & $3-77$ & $73 \ddagger$ \\
\hline Erythrocyte protoporphyrin $(\mu \mathrm{g} / \mathrm{g} \mathrm{Hb})$ & $4 \cdot 1$ & $2 \cdot 2$ & $1 \cdot 6-15 \cdot 0$ & $59 \S$ \\
\hline Serum ferritin $(\mu \mathrm{g} / 1)$ & $\begin{array}{l}37 \\
17 \cdot 8 \|\end{array}$ & 60 & $2-450$ & 419 \\
\hline \multicolumn{5}{|c|}{ Non-pregnant women $(n 95)$} \\
\hline Haemoglobin $(\mathrm{Hb} ; \mathrm{g} / \mathrm{l})$ & 121 & 12 & $78-140$ & $39 *$ \\
\hline Mean corpuscular volume (f) & $84 \cdot 2$ & $6 \cdot 9$ & $59-99$ & $22 \dagger$ \\
\hline Percent saturation of transferrin & $18 \cdot 1$ & $5 \cdot 8$ & $3-44$ & $43+$ \\
\hline Erythrocyte protoporphyrin $(\mu \mathrm{g} / \mathrm{g} \mathrm{Hb})$ & $3 \cdot 0$ & $1 \cdot 2$ & $1 \cdot 3-12 \cdot 1$ & $38 \S$ \\
\hline Serum ferritin $(\mu \mathrm{g} / \mathrm{l})$ & $\begin{array}{l}64 \\
40 \cdot 1 \|\end{array}$ & 63 & $1-330$ & 139 \\
\hline
\end{tabular}

* Lower limits of normal for haemoglobin concentrations $(\mathrm{g} / \mathrm{l})$ were 110 for pregnant women, 120 for non-pregnant women.

$\uparrow$ Lower limit of normal for mean corpuscular volume, $80 \mathrm{fl}$.

\$ Lower limit of normal for percentage saturation of transferrin, 16.

$\S$ Upper limit of normal for erythrocyte protoporphyrin level, $3 \mu \mathrm{g} / \mathrm{g} \mathrm{Hb}$.

Lower limit of normal for serum ferritin concentrations, $12 \mu \mathrm{g} / 1$.

\|| Geometric mean.

Table 3. Iron status and inflammatory syndrome in pregnant and non-pregnant Beninese women

\begin{tabular}{|c|c|c|c|}
\hline Group & Biochemical indices & $\begin{array}{c}\text { Percent of } \\
\text { pregnant women }\end{array}$ & $\begin{array}{l}\text { Percent of } \\
\text { menstruating } \\
\text { women }\end{array}$ \\
\hline Fe-sufficiency & $\begin{array}{l}\mathrm{SF}>12 \mu \mathrm{g} / 1 \text { and } \\
\mathrm{TS} \geqslant 16 \% \text { and } \\
\mathrm{EP} \leqslant 3 \mu \mathrm{g} / \mathrm{g} \mathrm{Hb}\end{array}$ & 11 & 39 \\
\hline Fe-depletion & $\mathrm{SF} \leqslant 12 \mu \mathrm{g} / 1$ & 3 & 1 \\
\hline Fe-deficiency & $\begin{array}{l}\mathrm{SF} \leqslant 12 \mu \mathrm{g} / 1, \text { combined with } \\
\mathrm{TS}<16 \% \text { or } \\
\mathrm{EP}>3 \mu / \mathrm{g} / \mathrm{Hb}, \text { or both }\end{array}$ & $38 \cdot 5$ & 14 \\
\hline $\begin{array}{l}\text { Fe-deficiency and } \\
\text { inflammatory syndromes }\end{array}$ & $\begin{array}{l}\text { SF between } 13 \text { and } 50 \mu \mathrm{g} / 1 \text {, } \\
\text { combined with TS }<16 \% \text { or } \\
\mathrm{EP}>3 \mu \mathrm{g} / \mathrm{g} \mathrm{Hb} \text {, or both }\end{array}$ & 34 & 25 \\
\hline Inflammatory syndrome & $\begin{array}{l}\text { SF }>50 \mu \mathrm{g} / 1 \text {, combined with } \\
\text { TS }<16 \% \text { or } \\
\text { EP }>3 \mu \mathrm{g} / \mathrm{g} \mathrm{Hb} \text {, or both }\end{array}$ & $13 \cdot 5$ & 21 \\
\hline
\end{tabular}

SF, serum ferritin; TS, transferrin saturation; EP, erythrocyte protoporphyrin. 
Table 4. Measurements of folate status in pregnant Beninese women (n 126)

\begin{tabular}{|c|c|c|c|c|}
\hline & Mean & $\mathrm{SD}$ & $\begin{array}{c}\text { Geometric } \\
\text { mean }\end{array}$ & $\begin{array}{c}\text { Value } \\
\text { below normal } \\
(\%)\end{array}$ \\
\hline
\end{tabular}

* Lower limit of normal for erythrocyte folate, $160 \mu \mathrm{g} / \mathrm{l}$.

+ Lower limit of normal for serum folate, $3 \mu \mathrm{g} / 1$.

was observed in ninety-one $(73 \%)$ pregnant women and in thirty-nine $(41 \%)$ menstruating women. Fe-deficiency was present in $83 \%$ of anaemic pregnant women and in $43 \%$ of anaemic menstruating women. Prevalences of Fe-deficiency anaemia were respectively, $45 \%$ in pregnant women and $17 \%$ in menstruating women.

In pregnant women, $\mathrm{Hb}$ was correlated positively with packed cell volume $(r 0.79$, $P<0.001)$ and negatively with erythrocyte protoporphyrin $(r-0.53, P<0.001)$. Erythrocyte protoporphyrin was negatively correlated with mean corpuscular volume $(r-0.21$, $P<0.02)$ and positively correlated with leucocyte count $(r 0.31, P<0.001)$. Serum ferritin was correlated with transferrin saturation $(r 0.38, P<0.001)$ and leucocyte count $(r 0.28$, $P<0.001)$.

\section{Maternal folate status}

Means, with their standard deviations, and percentage of abnormal values for erythrocyte and serum folate concentrations, are shown in Table 4. Erythrocyte folate values were correlated with serum folate values $(r 0.56, P<0.001)$. Folate deficiency (defined as an erythrocyte folate level below $160 \mu \mathrm{g} / 1)$ was observed in fifty-seven $(45 \%)$ pregnant women and anaemia was associated with folate deficiency in thirty-three $(26 \%)$ cases. Fe-deficiency was associated with folate deficiency in forty-four $(35 \%)$ pregnant women.

Finally, $83 \%$ of cases of anaemia were associated with Fe-deficiency and $48 \%$ were associated with folate deficiency. Fe and folic acid deficiencies were associated with each other in $26 \%$ of anaemic women.

\section{Types of $\mathrm{Hb}$, and malarial infestation of mothers}

$\mathrm{Hb}$ was type AA in ninety-four $(75 \%)$ pregnant women, type AS in twenty $(16 \%)$ cases, type $\mathrm{AC}$ in ten $(8 \%)$ cases and type $\mathrm{SC}$ in two $(1 \%)$ cases. Percentages were similar in the control group of non-pregnant women. Homozygous sickle cell disease was not observed. The frequency of anaemia was not significantly different among the three main $\mathrm{Hb}$ types.

Plasmodium falciparum was found in blood thick film in $99 \%$ of pregnant women (and in $97 \%$ of the control group). Only $7 \%$ of pregnant women had moderate or high malarial infestation density (density of five trophozoites or more per microscopic field). Mean haemoglobin, frequency of anaemia, Fe and folic acid status were not related to the density of malarial infection.

\section{Newborn Fe and folic acid status}

Mean values, with their standard deviations, of the haematological indices of newborn babies are shown in Table 5. Apart from the total Fe-binding capacity, the means of the various measurements were significantly higher in the newborn infants than in their mothers $(P<0.05)$. No baby had a $\mathrm{Hb}$ level lower than $110 \mathrm{~g} / \mathrm{l}$ or a serum ferritin concentration of less than $12 \mu \mathrm{g} / \mathrm{l}$. Twelve $(10 \%$ ) had a Hb level less than $150 \mathrm{~g} / \mathrm{l}$ and $27 \%$ had a transferrin 
Table 5. Haematological indices for newborn Beninese infants (n 126)

\begin{tabular}{lccc}
\hline & Mean & SD & Range \\
\hline Haemoglobin $(\mathrm{g} / \mathrm{l})$ & 174 & 22 & $(113-230)$ \\
Packed cell volume $(\%)$ & $56 \cdot 0$ & $6 \cdot 7$ & $(39-76)$ \\
Mean corpuscular volume (fl) & $103 \cdot 2$ & $7 \cdot 8$ & $(76-149)$ \\
Percent saturation of transferrin & $19 \cdot 1$ & $9 \cdot 0$ & $(4 \cdot 4-52 \cdot 1)$ \\
Erythrocyte protoporphyrin $(\mu \mathrm{g} / \mathrm{g} \mathrm{Hb})$ & $4 \cdot 7$ & $2 \cdot 2$ & $(1 \cdot 6-12 \cdot 8)$ \\
Serum ferritin $(\mu \mathrm{g} / \mathrm{l})$ & 394 & 582 & $(40-5000)$ \\
Erythrocyte folate $(\mu \mathrm{g} / \mathrm{l})$ & $256^{*}$ & & $(166-990)$ \\
& 420 & 125 & \\
\hline
\end{tabular}

* Geometric mean.

Table 6. Measurements of iron status of newborn infants from Fe-sufficient and Fe-deficient Beninese mothers and from Beninese mothers with inflammatory syndrome (Mean values with their standard deviations)

\begin{tabular}{|c|c|c|c|c|c|c|}
\hline & \multicolumn{2}{|c|}{$\begin{array}{l}\text { Newborn from } \\
\text { Fe-sufficient } \\
\text { mothers } \\
(n \text { 14) }\end{array}$} & \multicolumn{2}{|c|}{$\begin{array}{l}\text { Newborn from } \\
\text { Fe-deficient } \\
\text { mothers } \\
(n 48)\end{array}$} & \multicolumn{2}{|c|}{$\begin{array}{l}\text { Newborn from } \\
\text { mothers with } \\
\text { inflammatory } \\
\text { syndrome } \\
(n 17)\end{array}$} \\
\hline & Mean & SD & Mean & SD & Mean & SD \\
\hline Haemoglobin $(\mathrm{Hb} ; \mathrm{g} / \mathrm{l})$ & 183 & 23 & $166^{*}$ & 20 & 178 & 16 \\
\hline Mean corpuscular volume (fl) & $108 \cdot 2$ & $13 \cdot 2$ & $102 \cdot 1^{*}$ & $8 \cdot 0$ & $106 \cdot 7$ & $4 \cdot 1$ \\
\hline Percentage saturation of transferrin & $20 \cdot 2$ & $11 \cdot 1$ & $16 \cdot 2$ & $8 \cdot 0$ & $20 \cdot 0$ & $14 \cdot 3$ \\
\hline $\begin{array}{l}\text { Erythrocyte protoporphyrin } \\
(\mu \mathrm{g} / \mathrm{g} \mathrm{Hb})\end{array}$ & $3 \cdot 7$ & $1 \cdot 2$ & $4 \cdot 9$ & $2 \cdot 4$ & $4 \cdot 4$ & $1 \cdot 5$ \\
\hline Serum ferritin $(\mu \mathrm{g} / 1) \dagger$ & \multicolumn{2}{|c|}{308} & \multicolumn{2}{|c|}{263} & \multicolumn{2}{|c|}{331} \\
\hline
\end{tabular}

* Mean value was significantly different from that for newborn infants from Fe-sufficient mothers $(P<0 \cdot 05)$.

+ Geometric mean.

saturation of less than $16 \%$. Erythrocyte protoporphyrin level was higher than $3 \mu \mathrm{g} / \mathrm{g} \mathrm{Hb}$ in $86 \%$ of cases. $\mathrm{Hb}$, serum $\mathrm{Fe}$, transferrin saturation, erythrocyte protoporphyrin and serum ferritin were not significantly different for babies born of anaemic and nonanaemic mothers.

Among babies, $\mathrm{Hb}$ levels were negatively correlated only with erythrocyte protoporphyrin $(r-0.26, P<0 \cdot 01)$. Hb concentration in newborn infants was positively correlated with maternal serum ferritin $(r 0.26, P<0.01)$. Measurements of Fe status of newborn infants from Fe-sufficient mothers (without inflammatory syndromes), Fe-deficient mothers and mothers with inflammatory syndrome (without Fe-deficiency) are shown in Table 6. $\mathrm{Hb}$ concentrations and mean corpuscular volume were significantly lower in newborn infants from Fe-deficient mothers $(P<0 \cdot 05)$. Erythrocyte folate in newborn infants was not related to maternal folate status. No differences were observed between the haematopoietic profiles of babies born of folate-deficient mothers and those born of normal mothers. Duration of gestation and birth weight were not related to maternal anaemia, nor to indicators of $\mathrm{Fe}$ or folic acid status. 


\section{DISCUSSION}

The results of the present study show that the frequency of anaemia (World Health Organization, 1972) is very high in pregnant women and in menstruating women. These results are in agreement with values from other studies carried out in Western Africa (Ojo, 1965; Simic, 1973; Murray et al. 1978). Factors affecting Hb concentration are multiple in Africa; Fleming (1982) suggested that malaria could lower the mean $\mathrm{Hb}$ concentration in the population by $20 \mathrm{~g} / 1$, causing profound anaemia in some subjects. In our study, chronic malarial infection was very common. The intensity of malarial parasitaemia was not related to $\mathrm{Hb}$ concentration, but only a few women had a high malarial infestation level. Sickle cell disease is also known to affect the Hb level (Fleming, 1982), but homozygous sickle cell diseases were not observed in our study. Haemoglobinopathies were mainly heterozygous and did not seem to contribute significantly to anaemia.

Fe-deficiency and folate deficiency were very common. However, the diagnosis of these deficiencies is difficult in a tropical context and requires an adequate, acceptable definition. Several methods of measuring Fe status are available (Cook et al, 1976; Cook \& Finch, 1979; Cook, 1982). Serum ferritin is considered as the most sensitive indicator of body $\mathrm{Fe}$ stores. Many studies with normal subjects, patients with Fe-deficiency and Fe overload have shown that the circulating ferritin concentration is directly proportional to the body level of Fe stores, as determined by phlebotomy, Fe absorption, and histological and biochemical determinations (Addison et al. 1972; Walters et al. 1973; Lipschitz et al. 1974; Bezwoda et al. 1979). Serum Fe level, transferrin saturation coefficent and erythrocyte protoporphyrin concentration are useful in indicating the adequacy of the Fe supply to the erythroid marrow (Cook, 1982). Anaemia and microcytosis reflect a final stage of Fe-deficiency and are useful for gauging the severity of Fe-deficiency.

The use of each of these indicators is problematic in the tropical context because of the frequency of confounding factors, particularly inflammatory syndromes and chronic infections which may be responsible of misclassification of the Fe status of subjects (Hecberg \& Galán, 1985). The most important problem in assessing Fe status in an African population is distinguishing chronic inflammation from Fe-deficiency. Inflammation is responsible for a decrease in the percentage of transferrin saturation, an increase in the erythrocyte protoporphyrin concentration and a very high elevation of the serum ferritin level (Dallman et al. 1979; Blake et al. 1981). The decrease in the percentage transferrin saturation is explained by a decreasing serum Fe level linked to immobilization of $\mathrm{Fe}$ in the reticulo-endothelial system during inflammation (Lipschitz et al. 1971, Elin et al. 1977). It was suggested that the rise in the serum ferritin level was caused by an augmentation of ferritin synthesis rather than by a release of ferritin from inflammatory cells (Kojnin \& Hershko, 1977). Thus, the use of transferrin saturation or erythrocyte protoporphyrin concentration, or both, as indicators of $\mathrm{Fe}$ status may cause an incorrect diagnosis of $\mathrm{Fe}$-deficiency in populations presenting inflammatory syndromes. Conversely, the use of serum ferritin could lead to a diagnosis of Fe-sufficiency in Fe-depleted subjects, and an underestimation of the prevalence of Fe-deficiency. The usual approach of separating normal from Fe-deficient subjects on the basis of only one criterion inevitably involves errors in the diagnosis of both normal and Fe-deficient subjects.

In inflammation, the rise in the serum ferritin level is usually very high, particularly compared with the modifications in transferrin saturation or the erythrocyte protoporphyrin level. A moderate rise in the serum ferritin concentration, combined with a low-percentage transferrin saturation or a high erythrocyte protoporphyrin level, or both, suggests Fe-deficiency in an inflammatory context (Hillmans \& Finch, 1985; Blake et al. 1981). This is consistent with Fleming's (1982) work in Nigeria. He observed that most women and 
children with markedly reduced Fe stores, as assessed by an estimate of stainable Fe in the bone marrow, had serum ferritin values below $50 \mu \mathrm{g} / 1$, while only a few of those with adequate $\mathrm{Fe}$ stores had serum ferritin values below this level. Using this approach, we found that Fe-deficiency and Fe-deficiency anaemia occurred in 73 and $45 \%$ of pregnant women respectively. The high frequency and the severity of Fe deficiency at the end of pregnancy may be explained by the low availability of dietary $\mathrm{Fe}$ intake and by the low level of $\mathrm{Fe}$ stores in women at the beginning of the pregnancy. In our control group $41 \%$ of menstruating women were Fe-deficient.

For assessment of folate status, erythrocyte folate is currently accepted as being the best test of tissue folate depletion which can be performed on the peripheral blood (Hoffbrand et al. 1966). Plasma folate level is considered to reflect the amount of folate absorbed during the recent period (Sauberlich et al. 1974). Moreover, plasma folate may be low in pregnancy even in the absence of tissue folate deficiency (Avery \& Ladger, 1970). Using erythrocyte folate as a criterion to diagnosis folate deficiency, we found $45 \%$ of pregnant women to be folate deficient.

Although it is clear that the transfer of Fe and folate from mother to fetus is an active process, it is not clear whether the fetus takes up optimal amounts of $\mathrm{Fe}$ and folate, or whether it takes up amounts proportional to levels available in mothers who are Fe- or folate-deficient, or both. In our study no differences were found in haematological profiles of babies born of anaemic and non-anaemic mothers, nor were differences observed according to the folate status of the mothers. However, differences were found according to the Fe status of the mothers when the Fe status was assessed by a number of indicators. Results in the literature on the relation between maternal and newborn Fe status are contradictory. Some authors have found such a relation (Fenton et al. 1977; Kelly et al. 1978; Puolakka et al. 1980) while others have not (Rios et al. 1975; Hussain et al. 1977; Van Eyjk et al. 1978; Gebre-Medhin \& Birgegard, 1981). These discrepancies may be explained by the different criteria used to define Fe-deficiency. In most of the studies, the mother's Fe status was defined by one or two biochemical measurements; this did not permit a valid classification of Fe-deficiency.

Results obtained in the present study suggest that Fe-deficiency is very common in pregnant women in Benin and represents the main cause of anaemia. The effect of the mother's Fe status on the haematological profile of the newborn infants was revealed when strict criteria, based on a combination of several independent biochemical indicators, were used to define Fe-deficiency.

For their excellent technical assistance, the authors acknowledge A. Houdegbé, G. Pembelot, E. Akuete, G. Ahouignan, I. Ayihounton, M. Amoussouga, J. Agossou, T. Dotou, M. Hodonou, S. Adankpo, V. Tossou Boco and G. Djoho Amou. This work was supported by a grant from the French Institut National de la Santé et de la Recherche Médicale (no. 838022).

\section{REFEREN CES}

Addison, G. M., Beamish, M. R., Hales, C. N., Hodkins, M., Jacobs, A. \& Lewellen, P. (1972). Journal of Clinical Pathology 25, 326-329.

Avery, B. \& Ledger, W. J. (1970). Obstetrics and Gynecology 35, 616-624.

Baker, S. J. \& DeMaeyer, E. M. (1979). American Journal of Clinical Nutrition 32, 368-417.

Bezwoda, W. R., Bothwell, T. H., Torrance, J. D., MacPhail, A. P., Charlton, R. W., Kay, G. \& Levin, J. (1979). Scandinavian Journal of Haematology 22, 113-120.

Blake, D. R., Waterworth, R. F. \& Bacon, P. A. (1981). British Medical Journal 283, 1147-1148.

Cook, J. D. (1982). Seminars in Hematology 19, 6-18.

Cook, J. D. \& Finch, C. A. (1979). American Journal of Nutrition 32, 2115-2119. 
Cook, J. D., Finch, C. A. \& Smith, N. J. (1976). Blood 48, 449-455.

Dallman, P. R., Siimes, M. A. \& Stekel, A. (1979). American Journal of Clinical Nutrition 33, 86-118.

DeMaeyer, E. M. \& Adiels-Tegman, M. (1985). World Health Statistics Quarterly 38, 302-316.

Elin, R. J., Wolff, S. M. \& Finch, C. A. (1977). Blood 49, 147-153.

Fenton, V., Cavill, I. \& Fisher, J. (1977). British Journal of Haematology 37, 145-149.

Fleming, A. F. (1982). Clinics in Haematology 1, 365-388.

Gebre-Medhin, M. \& Birgegard, G. (1981). Scandinavian Journal of Haematology 27, 247-252.

Giovanello, T. J., Di Benedetto, G., Palmer, D. W. \& Peters, T. Jr (1968). Journal of Laboratory and Clinical Medicine 71, $874-883$.

Hercberg, S. \& Galán, P. (1985). Revue Epidémiologie et Santé Publique 33, 228-239.

Hillmans, R. S. \& Finch, C. A. (1985). Red Cell Manual. Philadelphia: F. A. Davis.

Hoffbrand, A. V., Newcombe, F. A. \& Mollin, D. L. (1966). Journal of Clinical Pathology 19, 17-23.

Hussain, M. A. M., Gaafar, T. H., Laulicht, M. \& Hoffbrand, A. V. (1977). Archives of Disease in Childhood 46, 801-804.

Kelly, A. M., MacDonald, D. J. \& MacDougall, A. N. (1978). British Journal of Obstetrics and Gynecology 85, 338-343.

Kojnin, A. M. \& Hershko, C. (1977). British Journal of Haematology 37, 7-16.

Lipschitz, D. A., Cook, J. D. \& Finch, C. A. (1974). New England Journal of Medicine 290, 1213-1216.

Lipschitz, D. A., Simon, M. O., Lynch, S. R., Dugard, J., Bothwell, L. H. \& Charlton, R. W. (1971). British Journal of Haematology 21, 289-303.

Murray, M. J., Murray, A. B., Murray, N. J. \& Murray, M. B. (1978). British Journal of Nutrition 39, 627-630.

Ojo, O. A. (1965). Journal of Tropical Medicine and Hygiene 68, 32-38.

Puolakka, J., Janne, O. \& Vihlo, J. R. (1980). Acta Obstetrica et Gynecologica Scandinavica 95, 53-56.

Rios, E., Lipschitz, D. A., Cook, J. D. \& Smith, N. J. (1975). Pediatrics 55, 694-699.

Sauberlich, H. E., Skala, J. H. \& Dowdy, R. P. (1974). In Laboratory Tests for the Assessment of Nutritional Status, pp. 49-60 [J. W. Kingand and W. R. Faulkner, editors]. Cleveland: C.R.C. Press.

Simic, B. (1973). Food and Nutrition in Africa 10, 19-25.

Van Eyjk, H. G., Kross, M. J., Hoogendoorn, G. A. \& Wallenburg, H. C. S. (1978). Clinica Chimica Acta 83, $81-91$.

Vernet-Nyssen, M., Stephan, M., Peron, C., Volle, P. J. \& Ciret, P. (1983). In Colloque International de Biologie Prospective, pp. 227-230 [G. Siest, editor]. Paris: Masson.

Voller, A. \& de Savigny, D. (1981). In Techniques in Clinical Immunology, 2nd ed., pp. 157-168 [R. A. Thomson, editor]. London: Blackwell.

Walters, G. O., Miller, F. M. \& Worwood, M. (1973). Journal of Clinical Pathology 26, 770-772.

World Health Organization (1972). Nutritional Anaemias. Technical Report Series, no. 53. Geneva: WHO. 